\title{
Sensory biology of aquatic mammals
}

\author{
Wolf Hanke $\cdot$ Guido Dehnhardt
}

Received: 17 April 2013/Revised: 17 April 2013/Accepted: 18 April 2013/Published online: 5 May 2013

(C) Springer-Verlag Berlin Heidelberg 2013

Mammals that exclusively or partly live in the water have to cope with many physiological challenges, including challenges to their sensory systems. With the transition from the terrestrial to the aquatic environment, the different physical properties of air and water required new adaptations. Many mammalian species still live in both worlds, and we include these semi-aquatic mammals in our present definition of aquatic mammals. This special issue on the "Sensory biology of aquatic mammals" presents reviews and original studies on most major taxa that have been studied so far. The authors of original studies were encouraged to extend the discussion part to aid the nonspecialist reader in gaining an overview. This special issue is closely related to, but not exactly congruent with, an international conference with the same title that was held at the Marine Science Center in Rostock, Germany, in October 2012.

Marine mammals are the most extensively studied group of aquatic mammals. This is partly due to the fact that they represent the majority of species of aquatic mammals. Furthermore, marine mammals have often been more relevant economically to humans than freshwater species,

For special issue "Sensory biology of aquatic mammals".

W. Hanke $(\bowtie) \cdot$ G. Dehnhardt

Institute for Biosciences, Chair of Sensory and Cognitive

Ecology, Rostock University, Albert-Einstein-Strasse 3,

18059 Rostock, Germany

e-mail:wolf.hanke@uni-rostock.de

W. Hanke - G. Dehnhardt

Marine Science Center, Am Yachthafen 3a, 18119 Rostock, Germany e.g. in fisheries or whaling. And last but not least, people have a deeply rooted fascination for marine mammals. Maybe this is founded in the awareness that in the animal kingdom marine mammals are our close relatives, but at the same time they easily roam the last unexplored areas of the earth, where humans have not really managed to follow them even with modern technology.

The three major groups of marine mammals are the pinnipeds, the cetaceans and the sirenians (dugong and manatees). They are covered by original work and a review in this special issue. In addition, the polar bear (Ursus maritimus) and the sea otter (Enhydra lutris) are counted among the marine mammals. For information on the sensory biology of the polar bear, the reader is referred to Nachtigall et al. (2007); for the sea otter, to Murphy et al. (1990) and Ghoul and Reichmuth (2012); for marine mammals in general, to Supin et al. (2001), Dehnhardt (2002) and Thewissen and Nummela (2008). All major clades of marine mammals also include species that live fully or partly in fresh water, such as the Baikal seal (Pusa sibirica), two families of river dolphins (Iniidae and Platinistidae), dolphins of the genera Sotalia, Sousa and Orcaella, and the manatees (Trichechus).

Aquatic mammals originally living in limnic waters have also attracted a lot of attention. In the present special issue, they are represented by an insectivore and a monotreme, the American water shrew (see article by K. C. Catania) and the duck-billed platypus (see article by N. Czech-Damal et al.). The anatomy of some sensory systems was also studied in other originally limnic mammals: the otters of the genus Lutra, the hippopotamus (Hippopotamus amphibius), the beavers (Castor spp.) and the Australian water rat (Hydromys chrysogaster).

A particularly large body of scientific literature has dealt with the sense of hearing. This focus is partly due to the 
fact that sound potentially propagates farther through the water than light, electric fields and incompressible flow signals. This is however not a general rule. First, detecting an object of interest by passive listening requires that the sound emitted by the sender be sufficiently strong. This will be the case in acoustic communication. However, calmly swimming prey fish emit little sound, and cryptic and sessile animals may stay completely silent. Second, the attenuation of sound depends, among many other factors, on how deep the water is, that is on the distance from ground to surface. Sound travels most effectively when it is channelled between layers of different sound velocity or between the surface and the ground. By contrast, significant attenuation due to geometrical loss begins when the wavelength of the sound is more than four times the water depth (Urick 1996). This means that in a 30-m deep lake or coastal area sound frequencies of $120 \mathrm{~Hz}$ or less are severely dampened. This lower cut-off frequency is even higher above soft substrates (e.g. around $300 \mathrm{~Hz}$ over clayey silt; see Fig. 4.18 in $\mathrm{Au}$ and Hastings 2008). In a shallow creek or river, where water shrews or platypuses live, low-frequency sounds are hardly propagated and are additionally masked by noise from the running water. Unfortunately (for a predator), sounds produced by aquatic animals are often very low in frequency, as long as the animals are not communicating.

Not surprisingly, the vertebrates that invented hearing, namely the fishes, also invented vision for their aquatic environment. The eye of fishes, after an excursion to the land, has returned to the water several times independently with the various aquatic mammals. A group well studied in regard to anatomy and behaviour is the pinnipeds (reviewed by Hanke et al. 2009). These amphibious mammals possess good vision both in air and water, with a visual acuity comparable to that of a cat (in air the pinnipeds' acuity strongly depends on illumination) and outstanding absolute sensitivity. In this special issue, pinnipeds are represented by an original study on polarization vision in harbour seals (see article by F. D. Hanke et al.). It is shown that polarization vision does not provide cues for the animals' decision making under a range of experimental conditions. Polarization vision is unlikely to aid the harbour seals in prey capture, but it may still aid in large-scale orientation under cloudy skies. The visual system of cetaceans is well studied as well, predominantly in toothed whales. In cetaceans, the majority of studies are based on anatomical methods (Mass and Supin 2007). Behavioural studies include assessments of visual acuity in both air and water (Herman et al. 1975), which was found to be high, but not quite as high as in pinnipeds.

A specially adapted sensory system that uses sound and that has fascinated researchers since its discovery in the $1950 \mathrm{~s}$ is the echolocation system (biosonar) of odontocetes, i.e. toothed whales including dolphins (Kellogg 1958). Odontocetes emit short sound pulses (clicks) and perceive the echo returned from the object of interest using elaborate sound-emitting and receiving structures. Echolocation is based on high sound frequencies which are necessary to achieve good spatial resolution. High-frequency sound is attenuated in the water significantly more strongly than low- to medium-frequency sound. In addition, the target strength (the power of the target to backscatter or reflect sound) of many objects of interest is quite low, so that echolocating whales have to emit very loud sounds. This process is quite expensive, but in many situations has a larger range than other sensory systems, especially in markedly dark or turbid waters. Echolocation in odontocetes is so effective that they can detect a sphere of $8 \mathrm{~cm}$ diameter at distances exceeding $110 \mathrm{~m}$ (Au and Snyder 1980; Thomas and Turl 1990). They can also discriminate objects by material properties and shape (reviewed by Au 2000). We know all this from behavioural investigations, as invasive electrophysiology has not been applied in whales. More recently, the method of far-field (surface) auditory brainstem response (ABR) recording has been adapted for use in cetaceans. A review in this issue (see article by A. Supin and P. Nachtigall) describes how ABR recordings have been used to address gain control during echolocation in whales, a question otherwise only partly accessible. An original study (see article by P. T. Madsen et al.) carries the investigation of echolocation from the laboratory to the open sea using skillfully engineered recording devices attached to free-ranging whales.

Whales use hearing not only in the context of echolocation. Another important field in the study of these social animals is acoustic communication. Here, a review by V. Janik and L. Sayigh addresses signature whistles in dolphins. Signature whistles are individually distinctive vocalisations that depend on learning and show plasticity over the dolphin's lifetime. They do not depend on the individual's voice features and, therefore, may in some ways come to resemble what we think of as language.

Hearing in pinnipeds likewise has a range of functions including communication and orientation. Pinnipeds do not echolocate (Schusterman et al. 2000), at least not in the narrower sense of the definition that involves specialised sound-emitting and receiving structures. On the other hand, transitions between non-echolocating and echolocating animal species exist (and must have existed during evolution). Basic echolocation and the discrimination of obstacles are even possible in humans (Kellogg 1962). Echolocation in phocid seals, such as the Weddell seal (Leptonychotes weddellii), that frequently emit sound under water has been considered (Evans et al. 2003), and basic echolocation abilities, in the light of the studies on human subjects (Kellogg 1962), do not seem far-fetched. 
In pinnipeds, the amphibious lifestyle means that hearing both under water and in air must be considered. It has long been believed that pinnipeds are predominantly adapted for underwater hearing. This conjecture was put into perspective by Kastak and Schusterman (1998), who argued that amphibious hearing capabilities should be compared on the basis of sound pressure instead of sound intensity. Under this assumption, not all pinniped families would be more sensitive to underwater than aerial sound. In the present special issue, the article by C. Reichmuth et al. shows that aerial hearing in pinnipeds has generally been underestimated. Using a sound isolation chamber and three pinniped species with different ancestry and ecology, the authors show that aerial hearing of the pinnipeds can be as sensitive as that of terrestrial carnivores, while still possessing acute underwater hearing.

However, lacking elaborate echolocation abilities, pinnipeds appeared to have a rather limited range for prey detection under water. We found that phocid seals that inhabit turbid waters and to a lesser degree even otariid seals that tend to live in clearer waters can compensate for this by means of their vibrissal system. Prey fish leave a trail of water disturbances on their swimming path that may last for up to several minutes (Hanke et al. 2000; Hanke and Bleckmann 2004; Niesterok and Hanke 2013). Harbour seals (Phoca vitulina) are able to detect and follow such hydrodynamic trails (Dehnhardt et al. 2001). Subsequent studies showed that they can even further analyse the structure of water disturbances (Wieskotten et al. 2010, 2011). The detection and analysis of water movements by pinnipeds is described and reviewed by W. Hanke et al. in this issue.

The vibrissal system in pinnipeds also serves to detect and discriminate objects by direct touch (Dehnhardt 1990, 1994; Dehnhardt and Kaminski 1995; Dehnhardt and Dücker 1996). In this issue, a behavioural study by R. Grant et al. elucidates aspects of the mechanisms of size discrimination in a matching-to-sample experiment.

Vibrissae are also present in most other marine mammals, with the exception of adult toothed whales. Sirenians or sea cows (Sirenia), primarily investigated in the Florida manatee (Tricheus manatus), have numerous and diverse facial vibrissae that are so highly innervated that a high sensitivity to mechanical stimuli has been proposed (Reep et al. 1998). Vibrissae are even present on the whole postcranial body of manatees, so that a function similar to that of the fish lateral line has been discussed (Reep et al. 2002). In this special issue, an original study by J. Gaspard, G. B. Bauer and others addresses the question of how sensitive the facial vibrissae are to water movements. According to previous studies, manatees are well able to discriminate textures using their vibrissal system for direct touch (Bachteler and Dehnhardt 1999; Bauer et al. 2012).
Chemical senses in aquatic mammals have also been addressed in a number of studies. In whales, olfaction has sometimes been considered rudimentary, but there are anatomical indications for a functioning olfactory system at least in mysticetes (Thewissen et al. 2011). So far, there are no behavioural studies in whales. Pinnipeds smell dimethyl sulphide, a substance that indicates the presence of decaying plants and thus zones of zooplankton and fish abundance. Their sensitivity surpasses that of humans a million times (Kowalewsky et al. 2006). They can also discriminate between water of different degrees of salinity (Sticken and Dehnhardt 2000). Insectivores have developed a method to actually smell under water: they emit air bubbles that stay attached to the nose and then retract them. In this way, odorants are transferred from the water to the sensory epithelium via the air bubble. This is called underwater sniffing (Catania 2006). In this special issue, chemical senses are addressed by an original paper by S. Kim, M. Amundin and M. Laska on the discrimination of olfactory cues by the South African fur seal (Eumetopias jubatus).

A recent discovery is the electrical sense of certain dolphins (Czech-Damal et al. 2012). According to both anatomical and behavioural studies, the Guiana dolphin (Sotalia guianensis) can detect electrical fields of a strength produced by typical benthic prey fish. This kind of passive electrodetection is well known in several groups of carnivorous fish, such as sharks, rays and catfish. Apart from the Guiana dolphin, the only other mammals that are known to detect electric fields are monotremes, the platypus and the echidnas. N. Czech-Damal, W. Hanke and others provide a review of our results on the Guiana dolphin and a comparison with previous work on monotremes in this issue.

In addition to studies of sensory biology, the question of consciousness in dolphins is addressed in this special issue in a review by H. Harley. Consciousness in animals (and likewise in humans) is difficult to grasp, let alone to investigate and even difficult to define precisely. It may well stay the final frontier of brain research for decades to come. It is, however, commonly believed that there is a close connection between sensory processes and consciousness (Searle 1998).

The articles in this special issue, each in their own way, introduce the reader to the most exciting topics in aquatic mammal sensory biology. We are grateful to the authors and the reviewers for their time and effort, and to the editor-in-chief F. G. Barth for his support and interest.

Acknowledgments We thank the German Research Foundation (Ha4411/11-1) and the Office of Naval Research Global (N62909-121-1113) for supporting the conference "Sensory Biology of Aquatic Mammals" at the Marine Science Center Rostock in October 2012 that accompanied this special issue. 


\section{References}

Au WWL (2000) Echolocation in whales and dolphins. In: Au WWL, Popper AN, Fay RR (eds) Hearing in whales and dolphins. Springer, New York, pp 364-408

Au WWL, Hastings MC (2008) Principles of marine bioacoustics. Springer, New York

Au WWL, Snyder KJ (1980) Long-range target detection in open waters by an echolocating Atlantic bottlenose dolphin (Tursiops truncatus). J Acoust Soc Am 68:1077-1084

Bachteler D, Dehnhardt G (1999) Active touch performance in the Antillean manatee: evidence for a functional differentiation of facial tactile hairs. Zoology 102:61-69

Bauer GB, Gaspard JC III, Colbert DE, Leach JB, Stamper SA, Mann D, Reep R (2012) Tactile discrimination of textures by Florida manatees (Trichechus manatus latirostris). Mar Mamm Sci 28:E456-E471

Catania KC (2006) Olfaction-underwater 'sniffing' by semi-aquatic mammals. Nature 444:1024-1025

Czech-Damal NU, Liebschner A, Miersch L, Klauer G, Hanke FD, Marshall C, Dehnhardt G, Hanke W (2012) Electroreception in the Guiana dolphin (Sotalia guianensis). Proc R Soc B 279:663-668

Dehnhardt G (1990) Preliminary results from psychophysical studies on the tactile sensitivity in marine mammals. In: Thomas JA, Kastelein RA (eds) Sensory abilities of cetaceans. Plenum Press, New York, pp 435-446

Dehnhardt G (1994) Tactile size discrimination by a California sea lion (Zalophus californianus) using its mystacial vibrissae. J Comp Physiol A 175:791-800

Dehnhardt G (2002) Sensory systems. In: Hoelzel AR (ed) Marine mammal biology. Blackwell Publishing, Oxford, pp 116-141

Dehnhardt G, Dücker G (1996) Tactual discrimination of size and shape by a California sea lion (Zalophus californianus). Anim Learn Behav 24:366-374

Dehnhardt G, Kaminski A (1995) Sensitivity of the mystacial vibrissae of harbour seals (Phoca vitulina) for size differences of actively touched objects. J Exp Biol 198:2317-2323

Dehnhardt G, Mauck B, Hanke W, Bleckmann H (2001) Hydrodynamic trail following in harbor seals (Phoca vitulina). Science 293:102-104

Evans WE, Thomas JA, Davis RW (2003) Vocalizations from Weddell seals (Leptonychotes weddellii) during diving and foraging. In: Thomas JA, Moss CF, Vater M (eds) Echolocation in bats and dolphins. University of Chicago Press, Chicago, pp 541-547

Ghoul A, Reichmuth C (2012) Sound production and reception in southern sea otters (Enhydra lutris nereis). In: Popper AN, Hawkins AD (eds) The effects of noise on aquatic life. Springer, New York, pp 157-159

Hanke W, Bleckmann H (2004) The hydrodynamic trails of Lepomis gibbosus (Centrarchidae), Colomesus psittacus (Tetraodontidae) and Thysochromis ansorgii (Cichlidae) measured with scanning particle image velocimetry. J Exp Biol 207:1585-1596

Hanke W, Brücker C, Bleckmann H (2000) The ageing of the lowfrequency water disturbances caused by swimming goldfish and its possible relevance to prey detection. J Exp Biol 203:1193-1200

Hanke FD, Hanke W, Scholtyssek C, Dehnhardt G (2009) Basic mechanisms in pinniped vision. Exp Brain Res 199:299-311

Herman LM, Peacock MF, Yunker MP, Madsen CJ (1975) Bottlenosed dolphin: double-slit pupil yields equivalent aerial and underwater diurnal acuity. Science 189:650-652
Kastak D, Schusterman RJ (1998) Low-frequency amphibious hearing in pinnipeds: methods, measurements, noise, and ecology. J Acoust Soc Am 104:2216-2228

Kellogg WN (1958) Echo ranging in the porpoise. Science 128:982-988

Kellogg WN (1962) Sonar system of the blind. Science 137:399-404

Kowalewsky S, Dambach M, Mauck B, Dehnhardt G (2006) High olfactory sensitivity for dimethyl sulphide in harbour seals. Biol Lett 2:106-109

Mass AM, Supin AY (2007) Adaptive features of aquatic mammals' eye. Anat Rec 290:701-715

Murphy CJ, Bellhorn RW, Williams T, Burns MS, Schaeffel F, Howland HC (1990) Refractive state, ocular anatomy, and accommodative range of the sea otter (Enhydra lutris). Vision Res 30:23-32

Nachtigall PE, Supin AY, Amundin M, Roken B, Moller T, Mooney TA, Taylor KA, Yuen M (2007) Polar bear Ursus maritimus hearing measured with auditory evoked potentials. J Exp Biol 210:1116-1122

Niesterok B, Hanke W (2013) Hydrodynamic patterns from fast-starts in teleost fish and their possible relevance to predator-prey interactions. J Comp Physiol A 199:139-149

Reep RL, Marshall CD, Stoll ML, Whitaker DM (1998) Distribution and innervation of facial bristles and hairs in the Florida manatee (Trichechus manatus latirostris). Mar Mamm Sci 14:257-273

Reep RL, Marshall CD, Stoll ML (2002) Tactile hairs on the postcranial body in Florida manatees: a mammalian lateral line? Brain Behav Evol 59:141-154

Schusterman RJ, Levenson DH, Reichmuth CJ, Southall BL (2000) Why pinnipeds don't echolocate. J Acoust Soc Am 107: 2256-2264

Searle JR (1998) How to study consciousness scientifically. Brain Res Rev 26:379-387

Sticken J, Dehnhardt G (2000) Salinity discrimination in harbour seals: a sensory basis for spatial orientation in the marine environment? Naturwissenschaften 87:499-502

Supin AY, Popov VV, Mass AM (2001) The sensory physiology of aquatic mammals. Kluwer, Boston

Thewissen JGM, Nummela S (eds) (2008) Sensory evolution on the threshold-adaptations in secondarily aquatic vertebrates. University of California Press, Berkeley

Thewissen JGM, George J, Rosa C, Kishida T (2011) Olfaction and brain size in the bowhead whale (Balaena mysticetus). Mar Mamm Sci 27:282-294

Thomas JA, Turl CW (1990) Echolocation characteristics and range detection threshold of a false killer whale (Pseudorca crassidens). In: Thomas JA, Kastelein R (eds) Sensory abilities of cetaceans. Plenum Press, New York, pp 321-334

Urick RJ (1996) Principles of underwater sound. Peninsula Publishing, Los Altos

Wieskotten S, Dehnhardt G, Mauck B, Miersch L, Hanke W (2010) Hydrodynamic determination of the moving direction of an artificial fin by a harbour seal (Phoca vitulina). J Exp Biol 213:2194-2200

Wieskotten S, Mauck B, Miersch L, Dehnhardt G, Hanke W (2011) Hydrodynamic discrimination of wakes caused by objects of different size or shape in a harbour seal (Phoca vitulina). J Exp Biol 214:1922-1930 